\title{
Finite Element Analysis of IH Module
}

\author{
Bob Wands
}

\section{Introduction}

The purpose of this work is to find the stresses and deflections in the major structural components of a proposed inner hadronic (IH) module. The module uses a small diameter (nominally 3 inch i.d.) inner tube with $1 / 8$ in wall thickness which supports 38 tons of calorimetric instrumentation both when the module is lifted by one endplate, as required for installation into the $\mathrm{EC}$ cryostat, and when the module is in its operational orientation. In addition to this loading, the assembly procedure includes an axial preloading which will produce a force equivalent to a uniform pressure of $20 \mathrm{psi}$ on the module endplates. It is important to understand the module stresses under these loads.

This work is primarily to establish the feasibility of the proposed design, and does not consider weld design, tolerances, and other important design details.

\section{The Finite Element Model}

Two ANSYS finite element models were created based on the module dimensions and weights shown in Fig. 1.

1. Model 1. This is a three-dimensional model of one-half of the module. It is used to find the primary stresses in the outer skin, and also the stresses in the inner tube due to axial preload (The primary stresses in the inner tube are found from Model 2). Model 1 includes only the structural components of the module, 
and not the actual calorimeter cells. The internal structural plates were constrained by nodal coupling to the inner tube such that only radial forces could be developed with which to react to the cell loading. It was assumed that the weight of the cells could be accounted for by applying an appropriate mass density to the upper portion of the inner tube, and using a global acceleration in the ANSYS program. All components were considered to be steel. The Young's modulus of the outer skin of the module was reduced by a factor of 0.79 to account for the holes in the skin, which reduce its volume by $21 \%$. Two loadings were considered: 1) Cantilevered lifting from one endplate, and 2) 20 psi preloading pressure on the endplates. The operational loading of the module is not considered in this model since it can be shown that the cantilever stresses are greater than the operational stresses for the outer shell, and the inner tube will see little difference between the two loadings.

This model is shown in Fig. 2.

2. Model 2. This is a refined model of a four inch length of the 3 in. dia. tube in the center of the module. Symmetry is assumed at the ends of the section, and the model applies equally well to the lifting and operational loading cases. The tube was assumed to be Inconel 718. This model refined the assumptions of the first model by using a more exact approximation to the way in which the calorimeter plates transfer their load to the 3 in. dia. tube, and provided more accurate information on primary tube stresses. The calorimeter plates themselves were approximated in the model, and allowed to contact the tube through compression-only "gap" type elements. The large deflection option of ANSYS was used, which applied the loading slowly and updated the stiffness matrix during the solution to reflect any change in stiffness due to change in shape. This should provide some indication of the stability of the tube/plate structure. The model is shown in Fig. 3. 


\section{$\underline{\text { Results }}$}

\section{Model 1.}

The stresses in the outer tube as calculated by Model 1 are given in Table I for the pressure only, lifting only, and combined loadings. The preloading stresses are separated from the stresses induced by lifting because they are secondary stresses; that is, if any yielding occurs under preload, the result is to reduce the preload force. Therefore, the load cannot follow the strains, and the stresses cannot cause failure of the module if a ductile material is used.

Stresses in the outer tube will be evaluated in a manner similiar to AISC Steel Construction Code procedures, with a maximum allowable stress in tension of $0.6 \mathrm{~S}_{\mathrm{y}}$, and a maximum combined membrane plus bending stress of $0.67 \mathrm{~S}_{\mathrm{y}}$. The outer tube is assumed to be SS304 stainless steel with $\mathrm{S}_{\mathrm{y}}=\mathbf{3 5 0 0 0}$ psi. The primary membrane stresses in the outer tube will then be allowed to reach $18000 \mathrm{psi}$, and the primary membrane plus bending stresses will be allowed to reach 20100 psi.

The secondary stresses due to preload will be evaluated according to the ASME Boiler and Pressure Vessel Code procedures, since the AISC Code does not provide extensive guidance for such stresses. The sum of the primary stresses and the secondary stresses induced by preload will be allowed to reach $2 \mathrm{~S}_{\mathrm{y}}$, or $60000 \mathrm{psi}$, which is the limit imposed by the ASME Code for ductile materials. This limit is based on a "shakedown" criterion which assures that the structure will behave elastically after a few loading cycles.

Preloading induces a uniform axial stress in the outer tube of 4300 psi. The maximum bending stress in the outer tube resulting from lifting only is 14200 psi. The combined bending stress for preloading and lifting is then $18500 \mathrm{psi}$, which is within the allowable of $20100 \mathrm{psi}$ even if the preloading stress is classified as primary.

The shear stress in the outer tube is a maximum of $11300 \mathrm{psi}$ for the lifting load case, and occurs at the junction of the outer shell and 
the backing plate at the supported end. The finite element model included a lifting force on the inner tube also, in order to simulate a boss inserted into the module. It is of interest to calculate the shear stress for the case of the shell being lifted at the outer circumference of the backplate only. This calculation is performed in Appendix A and indicates the maximum shear stress to be $11900 \mathrm{psi}$. It is recommended in Ref. 1 that the maximum shear stress in a cylindrical shell at a support not exceed 0.8 times the allowable stress in tension, or $14400 \mathrm{psi}$. The shear in the outer tube is within this limit. The outer tube should not be perforated in the vacinity of the junction with the outer plate for a distance of at least four inches from the junction. This allows the shear force to decrease sufficiently to ensure that the reduced section can sustain the resulting shear stress.

The inner tube has a uniform axial stress due to preloading of 22500 psi. This stress will be superimposed over the stresses calculated in the inner tube by Model 2 to evaluate performance.

The deflections resulting from preloading and lifting loads are shown in Figs. 4 and 5.

\section{Model 2.}

Model 2 converged after eight iterations, and gave no indication that collapse would occur provided the material used remained elastic at the stresses resulting from the loads.

The alloy assumed in this model is Inconel 718 with a minimum

yield stress $S_{y}$ of $170 \mathrm{ksi}$, and a minimum ultimate stress $S_{u}$ of $200 \mathrm{ksi}$.

The model assumed a 0.125 in. thickness for the inner tube, and did not directly include the axial stress induced by the preload. The stress 
results can be scaled by the thickness, and the preload stress from Model 1 can be added during the calculation of stress intensity to generalize the results and choose an appropriate inner tube wall thickness.

The stress state is most severe at the base of the support plates. At these locations, a large compressive hoop stress coexists with a large tensile axial stress, producing a high stress intensity. The stresses will be evaluated using limits comparable to the AISC limits for primary membrane and bending stresses; that is, primary membrane stresses will be limited to $0.6 \mathrm{~S}_{\mathrm{y}}$, and primary membrane plus bending stresses will be limited to $0.67 \mathrm{~S}_{\mathrm{y}}$. The preloading stress in the tube is a secondary stress, as discussed above with reference to Model 1, and the combination of primary and secondary stresses will be limited to $2.0 \mathrm{~S}_{\mathrm{y}}$, or $340 \mathrm{ksi}$.

Appendix B contains the classification and evaluation of the stresses in the most highly stress portion of the tube. The highest stress intensity results on the inner surface of the tube when the primary and secondary stresses are combined and is $116 \mathrm{ksi}$. This is well below the limit of 340 ksi for such stresses. All other primary stresses fall within the stress limits, and show that an Inconel 718 tube with a $1 / 8$ in. wall should be adequate.

The deflections in the inner tube only are shown in Fig. 6.

\section{Conclusion}

The outer shell of the proposed module is adequate provided that the shell is not perforated any closer than four inches from the junction with the back plate used for lifting. The use of a boss in the inner tube during lifting does not result in significant reduction of shear loading on the outer shell.

The inner tube, if constructed of Inconel 718 , must have a wall thickness of 0.125 inches. The tube will not elastically or plastically collapse due to the calorimeter cell loadings.

The detailed design of the module must include, of course, appropriate sizing of welds, determination of tolerances, and other aspects not covered in this report. 


\section{Table I. Summary of Stress Results from Model I}

\begin{tabular}{|c|c|c|c|c|}
\hline Component & $\begin{array}{c}\text { Stress } \\
\text { Category }\end{array}$ & $\begin{array}{c}\text { Allowable } \\
\text { Stress }\end{array}$ & $\begin{array}{c}\text { Calculated } \\
\text { Stress }\end{array}$ & Location \\
\hline \multicolumn{5}{|c|}{ (Preloading) } \\
\hline Outer & Secondary & $60000 \mathrm{psi}$ & $4300 \mathrm{psi}$ & Uniform \\
\hline & Membrane & & & Axial Stress \\
\hline \multirow[t]{3}{*}{ Inner Tube } & Secondary & $60000 \mathrm{psi}$ & $22500 \mathrm{psi}$ & Uniform \\
\hline & & & & Axial Stress \\
\hline & \multicolumn{2}{|c|}{ (Lifting Only) } & & \\
\hline \multirow[t]{2}{*}{ Outer Shell } & $\begin{array}{l}\text { Primary } \\
\text { Membrane }\end{array}$ & 20100 psi & $14200 \mathrm{psi}$ & $\begin{array}{l}\text { Top of Tube } \\
\text { at Lift End }\end{array}$ \\
\hline & $\begin{array}{l}\text { Primary } \\
\text { Shear }\end{array}$ & 11900 psi & $14400 \mathrm{psi}$ & $\begin{array}{l}\text { Tube Side } \\
\text { at Lift End }\end{array}$ \\
\hline
\end{tabular}


Table I (cont'd)

$\begin{array}{ccccc}\text { Component } & \text { Stress } & \text { Allowable } & \text { Calculated } & \text { Location } \\ & \text { Category } & \text { Stress } & \text { Stress } & \end{array}$

(Combined Loading)

\begin{tabular}{|c|c|c|c|c|}
\hline Outer Tube & $\begin{array}{l}\text { Primary } \\
\text { Bending }+ \\
\text { Secondary } \\
\text { Membrane }\end{array}$ & $60000 \mathrm{psi}$ & $18500 \mathrm{psi}$ & $\begin{array}{l}\text { Top of Tube } \\
\text { at Lift End }\end{array}$ \\
\hline & $\begin{array}{l}\text { Primary } \\
\text { Shear }\end{array}$ & $11900 \mathrm{psi}$ & $14400 \mathrm{psi}$ & $\begin{array}{l}\text { Tube Side } \\
\text { at Lift End }\end{array}$ \\
\hline
\end{tabular}


(2)

Then, the maximum sheer flow $g$ is

$$
q_{\text {max }}=\frac{Q}{r \pi} \sin \left(\frac{\pi}{2}\right)=\frac{Q}{r \pi}
$$

and the maximum shear stress is

$$
\nabla_{\text {max }}=\frac{Q}{r \pi t}
$$

For the module outer shell

$$
\begin{aligned}
& Q=76000 \mathrm{lbs} \\
& r=34 \\
& t=0,06
\end{aligned}
$$

Then

$$
\tau_{\text {max }}=11900 \text { psi }
$$

Calculation assumes all shear is taken by outer shell. FE model also supports inner tube.

If shell is perforated at junction, $\tilde{\imath}=\frac{11900}{0.79}=15100$ psi.

If allowable is 14400, then shell should not be perforated for $\left[\frac{15100-14400}{15100}\right]=5^{\% 10}$ of length, or $\sim 4$ inches

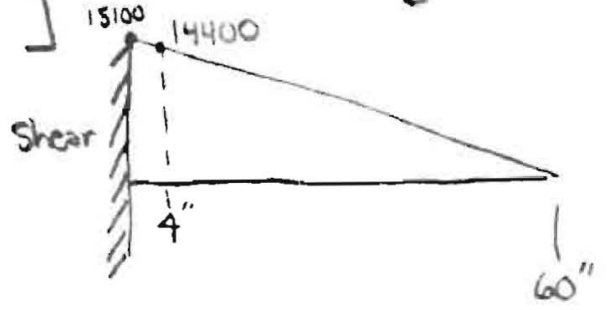




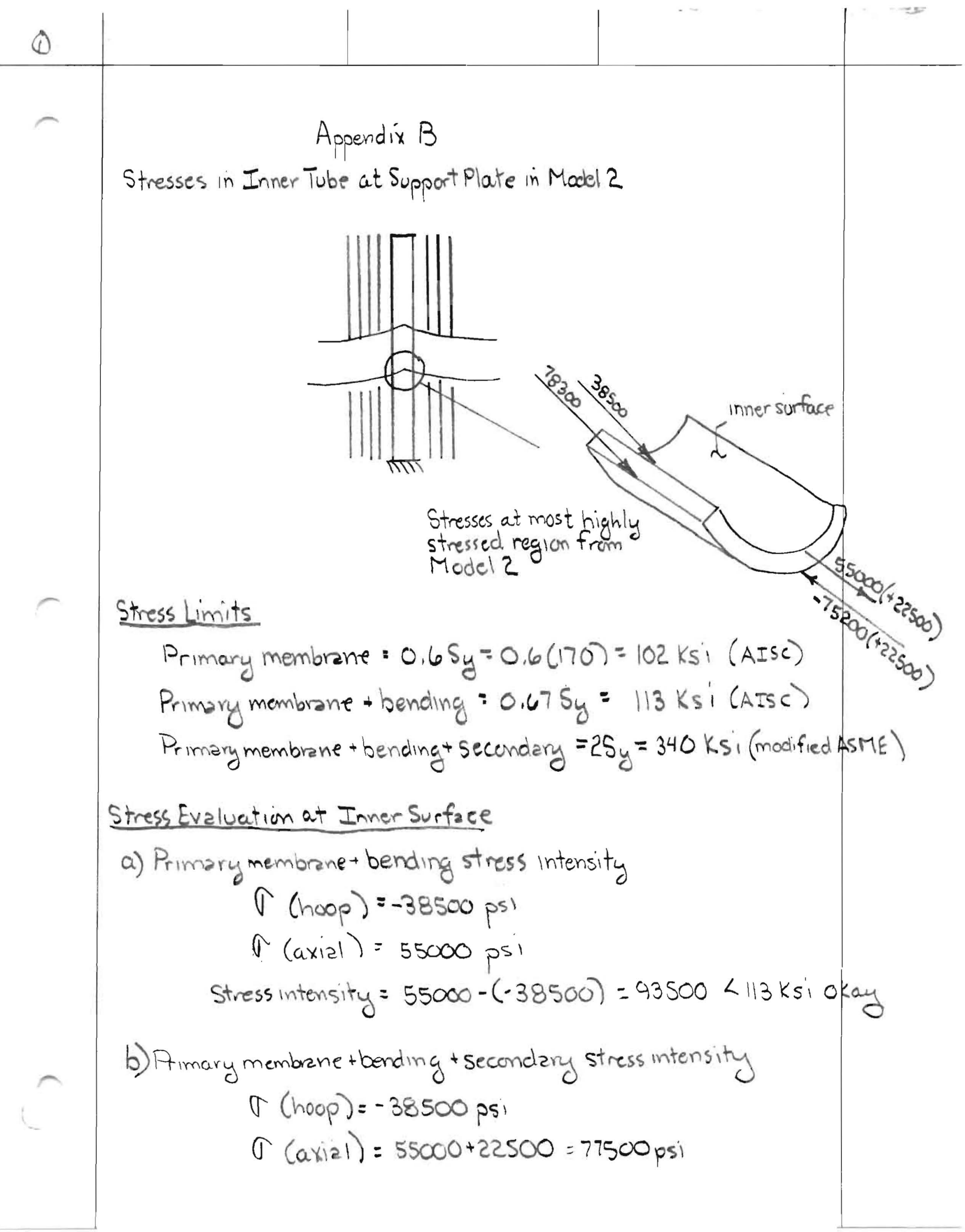




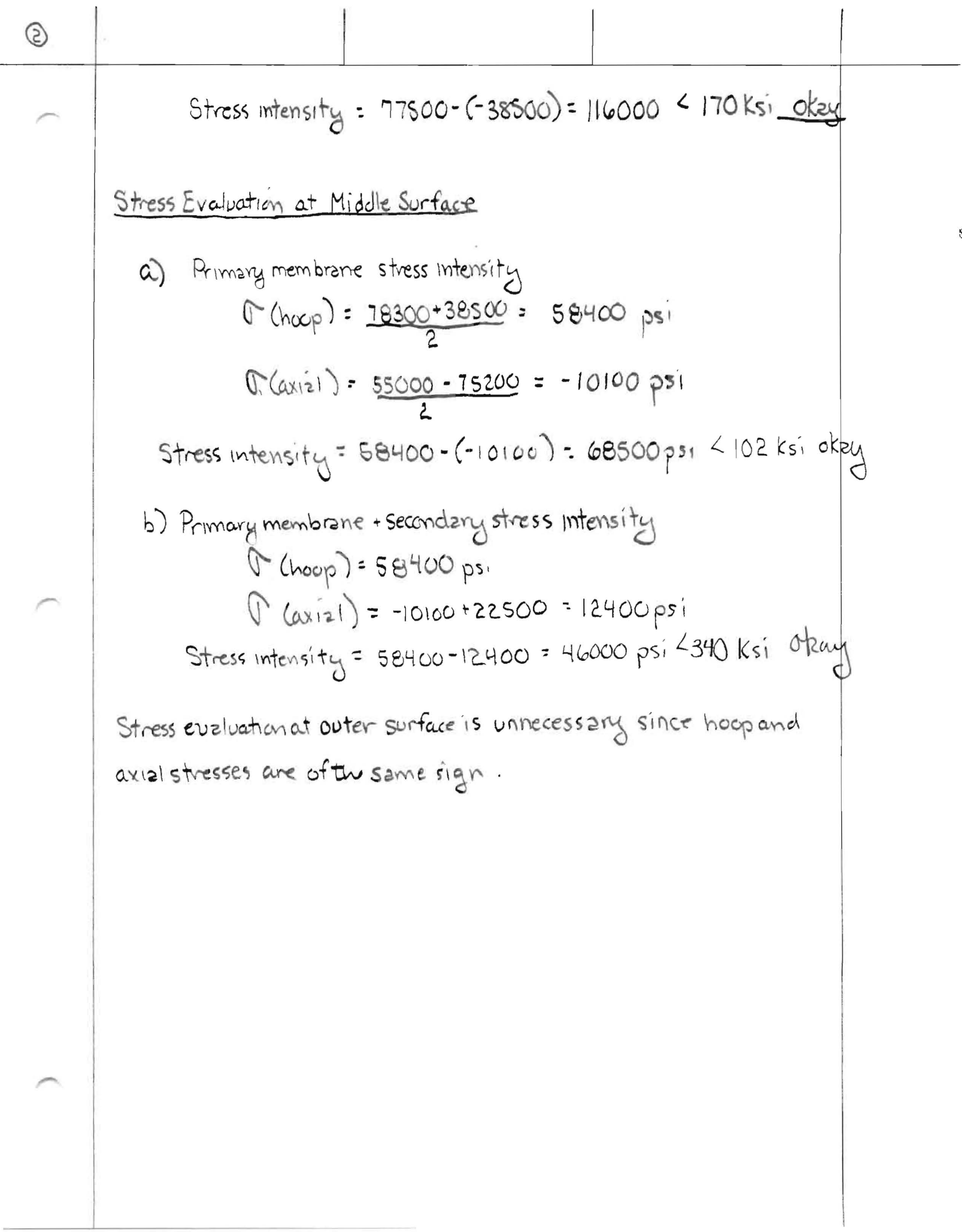




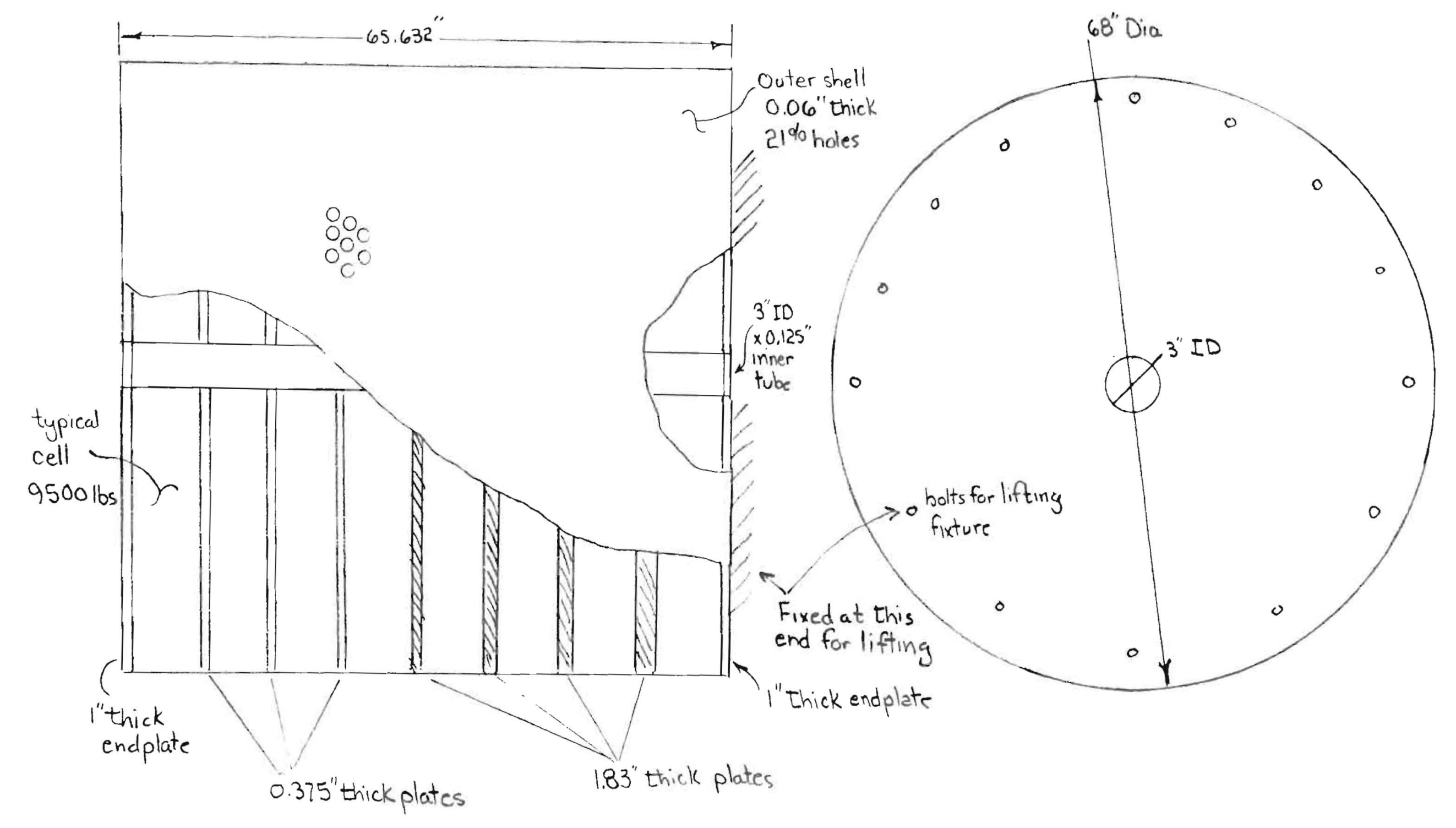

Fig 1. IH Module [Drwg. 3740.222-ME-222452 w/sorre additions] 


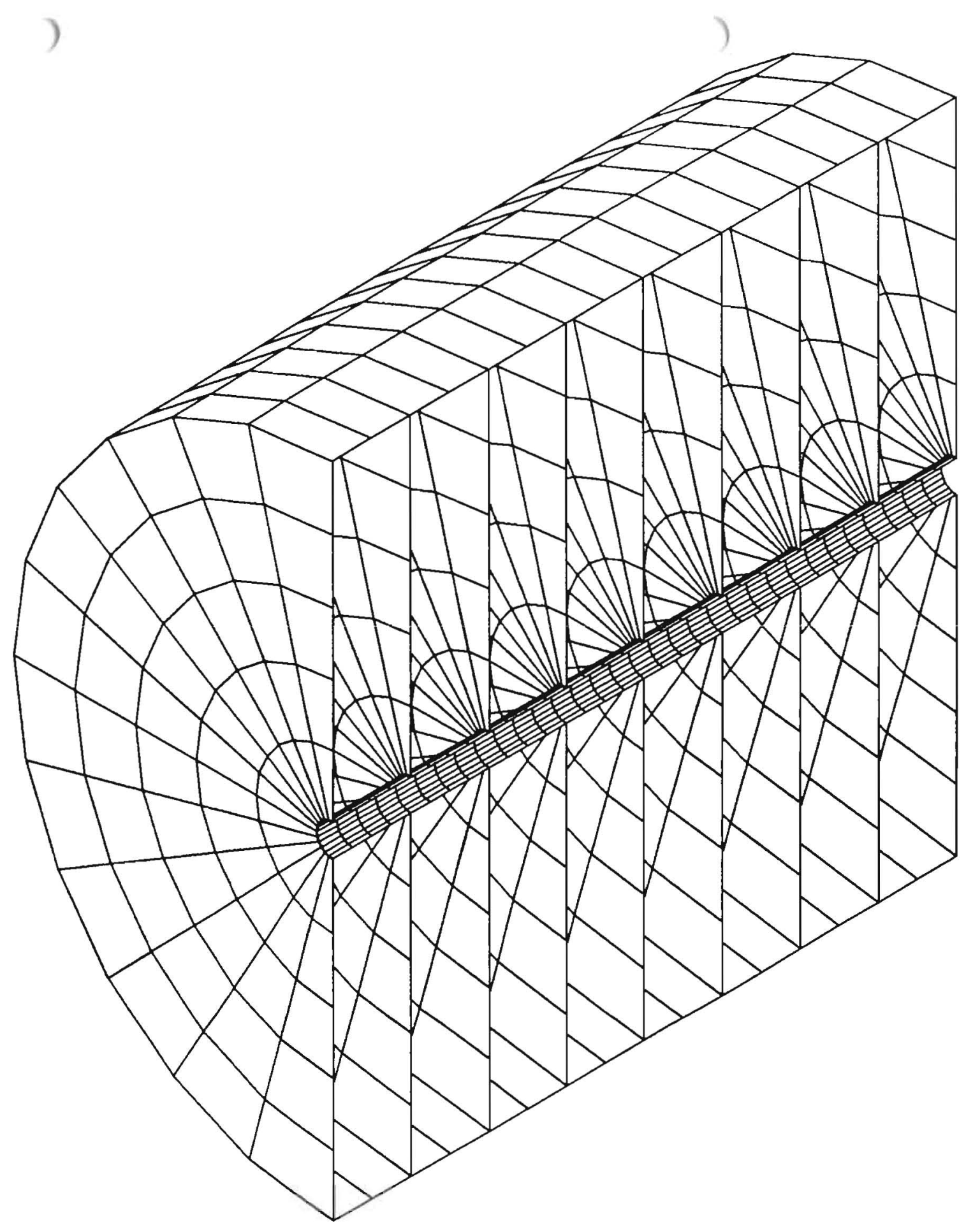

$\begin{array}{ll}\text { ANSYS } & \text {.2B } \\ \text { MAR } 19 & 1987 \\ 9: 00: 11\end{array}$

PLOT NO.

3

POST1 ELEMENTS

ORIG SCALING

$X \vee=1$

$Y=1$

$\mathrm{ZV}=1$

$\mathrm{DIST}=47$

$X F=-11.5$

$Y F=-1.03$

$Z F=-27.3$

HIDDEN

Fig 2. Finite Element Model 1 of IH module. 


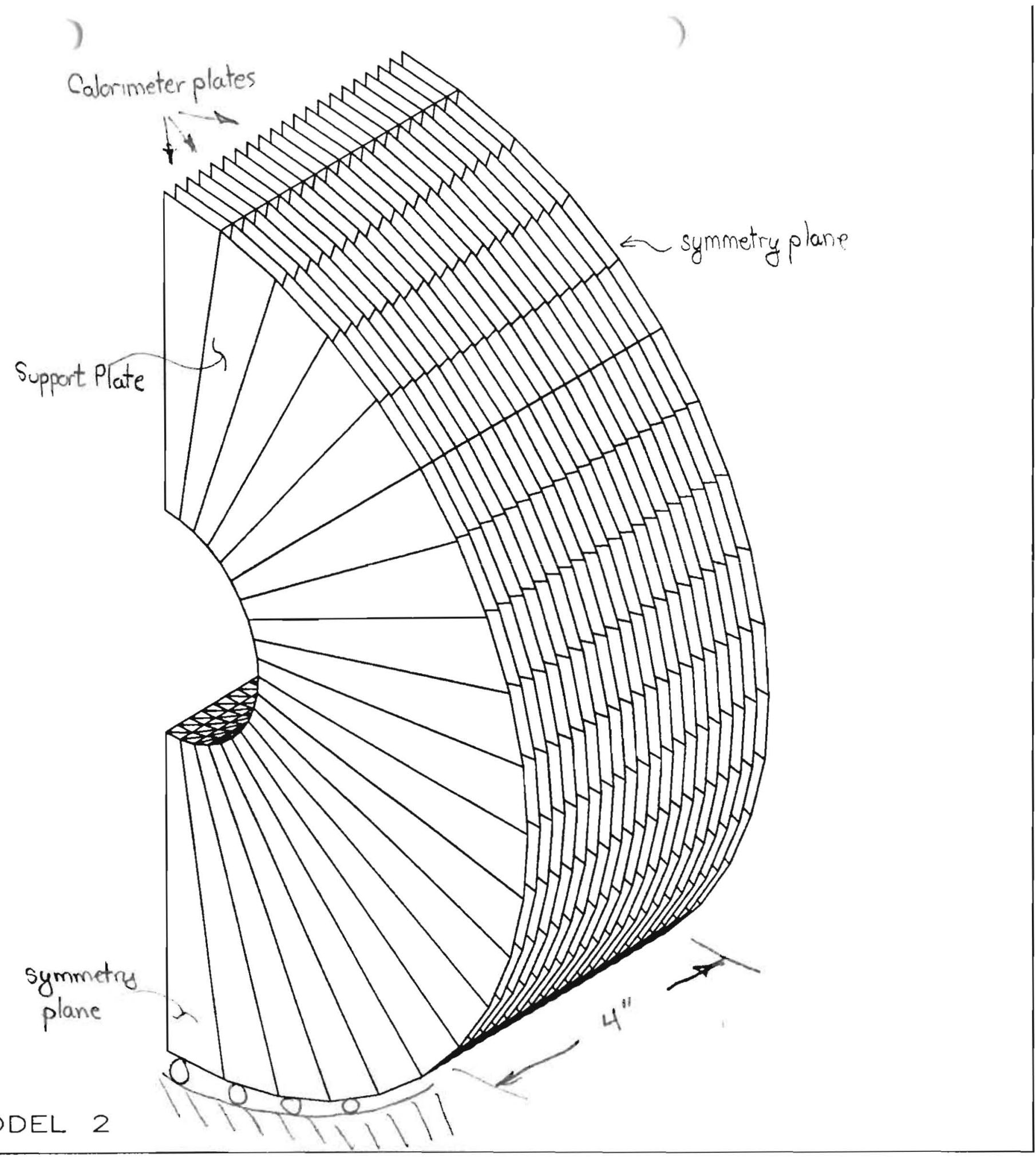

$\begin{array}{lc}\text { ANSYS } & \text {.2B } \\ \text { MAR } 19 & 1987 \\ \text { 1O:O8: } 13 \\ \text { PLOT NO. } 1 \\ \text { POST1 ELEMENTS }\end{array}$

ORIG SCALING

$X \vee=1$

$Y=1$

$\mathrm{ZV}=1$

$\mathrm{DIST}=6.65$

$X F=2.05$

$Y F=.18$

$Z F=-2.98$

HIDDEN

Fig3. Finite Element Model2 $4^{\prime \prime}$ Length of Inner tube w/support plate 


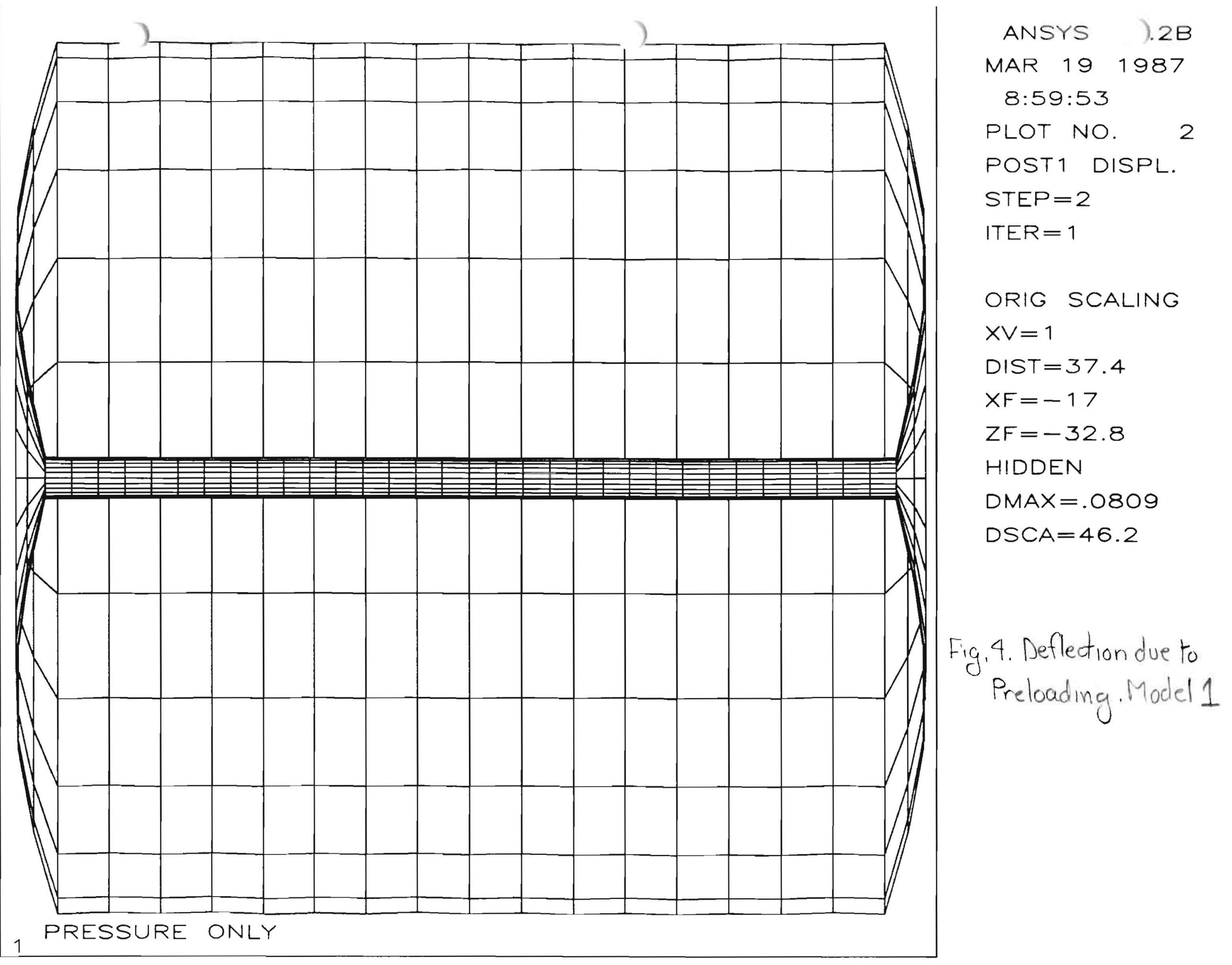




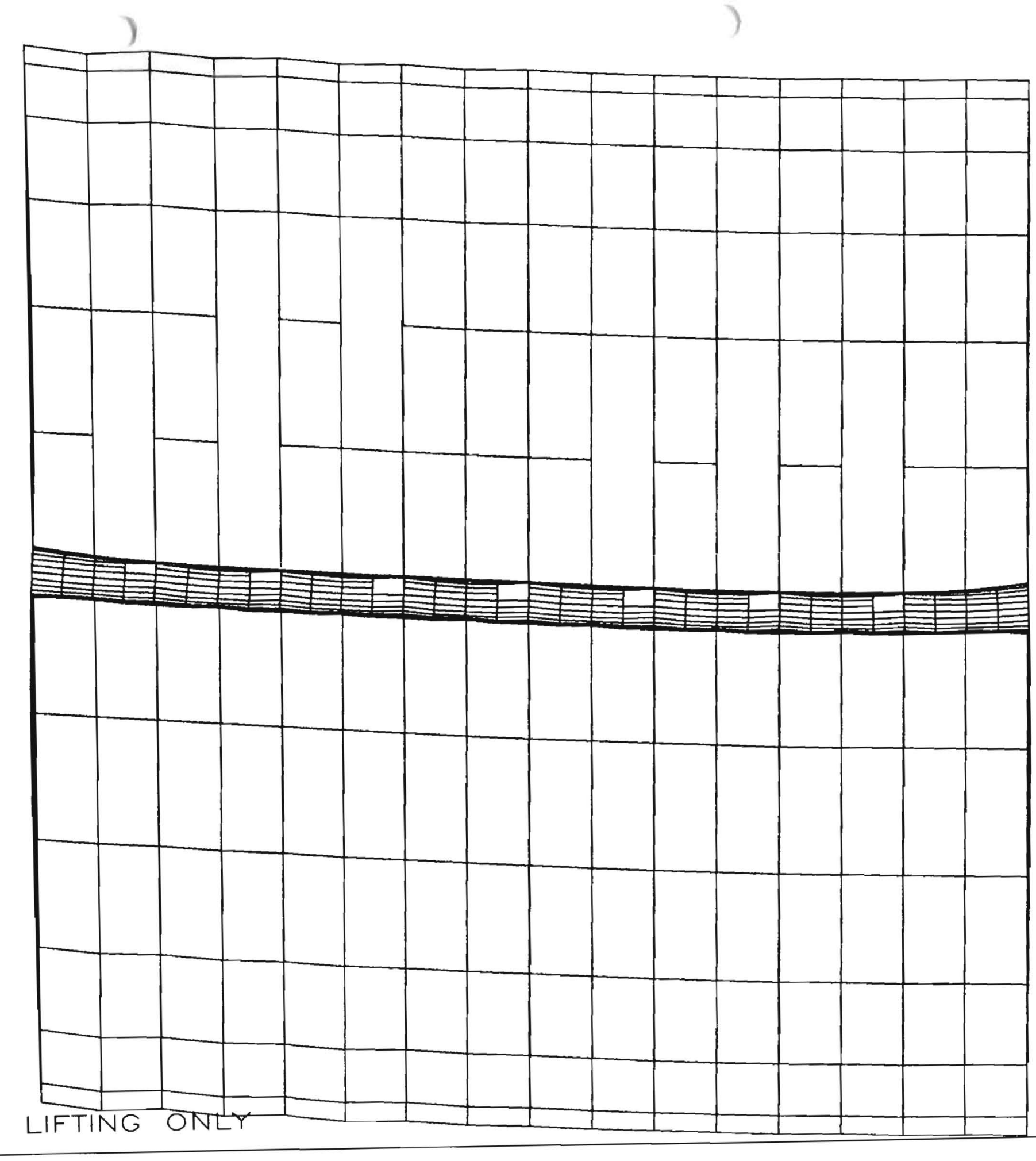
ANSYS $) .2 B$
MAR 191987
$8: 54: 38$

PLOT NO. 1

POST1 DISPL.

$S T E P=1$

ITER $=1$

ORIG SCALING

$X \vee=1$

$\mathrm{DIST}=37.4$

$X F=-17$

$Z F=-32.8$

HIDDEN

$D M A X=.073$

$\mathrm{DSCA}=51.2$

Fig5 Deflectiondueto lifting. Model 1 

MAR $19 \quad 1987$ 10:11:28

PLOT NO. 2

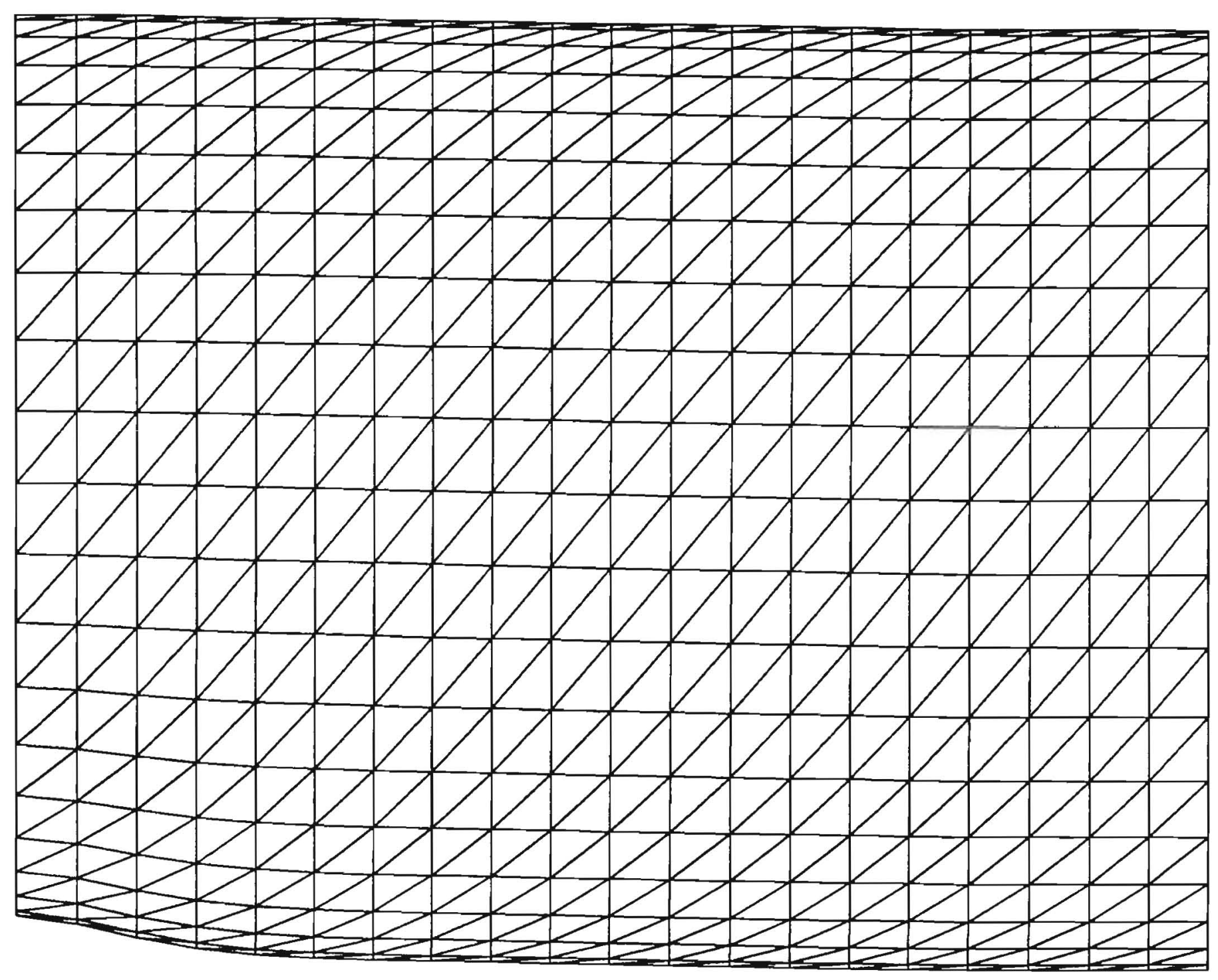

POST1 DISPL.

$S T E P=1$

ITER $=10$

ORIG SCALING

$X V=1$

$\mathrm{DIST}=2.2$

$X F=.775$

$Z F=-2$

HIDDEN

$D M A X=.0102$

$D S C A=21.5$

Fig6. Deflection of

Inner Tube Madel 2

MODEL 2 INNER TUBE DEFLECTED SHAPE 